\title{
Insulin Autoantibody Measurement
}

National Cancer Institute

\section{Source}

National Cancer Institute. Insulin Autoantibody Measurement. NCI Thesaurus. Code C119286.

The determination of the amount of insulin autoantibody in a biological specimen. 